\title{
TELEVISÃO ANALÓGICA VERSUS TELEVISÃO DIGITAL: A INTERATIVIDADE AMEAÇA A TV GENERALISTA?
}

\author{
MATEUS VILELA \\ PONTIFÍCIA UNIVERSIDADE CATÓLICA DO RIO GRANDE DO SUL \\ PORTO ALEGRE, RIO GRANDE DO SUL, BRASIL \\ E-MAIL: MATEUSDVILELA@GMAIL.COM
}

HTTP://DX.DOI.ORG/10.5902/2316882X20932 
TELEVISÃO ANALÓGICA VERSUS TELEVISÃO DIGITAL: A INTERATIVIDADE AMEAÇA A TV GENERALISTA?

Resumo: Interatividade não é um conceito novo na televisão, mas quanto maior a evolução tecnológica, maior são as possibilidades de uma experiência mais personalizada e única. Diante deste contexto, este ensaio discorre sobre a televisão generalista, investigando se a interação permitida pelo digital, coloca em risco não só o conteúdo generalista, mas o fortalecimento da democracia e do laço social propiciados pela TV aberta. Palavras-chave: Televisão generalista; interatividade; conteúdo.

\section{TV ANALÓGICA FRENTE A LA TELEVISIÓN DIGITAL: INTERACTIVI- DAD AMENAZA DE TV GENERALISTA?}

Resumen: La interactividad no es un concepto nuevo en la televisión, pero cuanto mayor sea la evolución tecnológica, mayores son las posibilidades de una experiencia más personalizada y única. En este contexto, este ensayo habla de la televisión generalista, que investigan la interacción permitida por la digital, pone en peligro no sólo el contenido general, sino el fortalecimiento de la democracia y los vínculos sociales habilitados por la TV abierta.

Palabras clave: televisión generalista; interactividad; contenido.

\section{ANALOGIC TV VERSUS DIGITAL TV: INTERACTIVITY THREATENS GENERALIST TV?}

Abstract: Interactivity is not a new concept in television, but the higher the technological evolution, the greater are the possibilities for a more personalized and unique experience. Given this context, this essay talks about the generalist television, investigating the interaction allowed by digital, endangers not only the general content, but the strengthening of democracy and the social bonds enabled by the open TV.

Keywords: Generalist television; interactivity; content. 


\section{INTRODUÇÃO}

As armações do vilão da novela, o sofrimento da mocinha, a matéria do telejornal, a gafe da apresentadora, o vencedor do reality show são pautas diárias não somente nos jornais, nas revistas e na internet, como também na fila da padaria, no supermercado e durante o almoço. Essa discussão atinge boa parte da população porque, ao oferecer um variado "cardápio" de programas, com diversos temas e assuntos, a televisão generalista exibe um "pouco de tudo", permitindo ao telespectador se informar não somente sobre o que ele quer saber, mas também, sobre o que os produtores julgam ser necessário tomar conhecimento. Assim, ao ver a TV generalista, o público se sente ligado a uma massa anônima que, simultaneamente, assiste o mesmo conteúdo e sobre o qual, a posteriori, podem conversar a respeito. É o que Dominique Wolton (2012) acredita ser a maior função da televisão generalista: construção do laço social e fortalecimento da democracia.

Diante desse cenário, a TV brasileira passa pelo processo de digitalização que, amparada pela tecnologia digital, oferece uma série de possibilidades. Melhoria na resolução de som e imagem, inclusão da interatividade a partir do próprio televisor, mobilidade e portabilidade são anunciadas como as possíveis novas características da televisão brasileira. Em última instância tais possibilidades poderão garantir a construção de várias programações, não lineares e mais participativas, tornando o "assistir TV" uma experiência mais personalizada e única.

Dessa forma, partindo da definição e da caracterização de Dominique Wolton sobre a televisão aberta generalista, o ensaio a seguir busca refletir se as possibilidades do digital sobre a TV recaracterizam e resignificam o meio televisivo. Em suma, discutiremos se o digital, através da interatividade, ameaça a televisão generalista e aberta do Brasil e, por conseguinte, o laço social e a democracia.

\section{A IMPORTÂNCIA DA TELEVISÃO GENERALISTA}

Um dos maiores desafios da sociedade contemporânea, para Dominique Wolton (2012), é administração das diferenças. Em um mundo onde a informação e a comunicação são cada vez mais personalizadas e onipresentes, há uma tendência natural ao aumento das diferenças entre os indivíduos, ou pelo menos uma maior evidência dessas diferenças, sejam

Rev.Cad. Comun. Santa Maria, v.21, n.1, art 2, p.45 de 57, jan/abr.2017 
elas sociais ou mesmo intelectuais. O aumento dos conteúdos de nichos também favorece que o indivíduo se limite aos grupos ao qual tem interesse mantendo um afastamento sobre outros temas que não são de sua predileção.

Uma das funções da televisão aberta, segundo o autor, é justamente o fato de oferecer ao espectador "um pouco de tudo". Ao assistir um telejornal, por exemplo, o público pode ser informado ao mesmo tempo, por exemplo, sobre esporte, economia, cultura, favorecendo um conhecimento mais amplo e completo sobre boa parte dos assuntos de seu país e do mundo. Para o teórico, a vantagem de mídias como o rádio e a televisão é conseguirem atuar tanto na esfera individual quanto na coletiva:

\begin{abstract}
A força das mídias generalistas é justamente de apoiar-se nas duas pontas da comunicação, a escala individual e a escala coletiva, enquanto as novas tecnologias se situam principalmente na escala individual. Por outro lado, as mídias generalistas, privilegiando a lógica da oferta, salientam a importância, para uma teoria da cultura, de uma posição normativa, que evidencia, contrariamente à ideologia atual da demanda, o quanto da emancipação cultural passa fortemente pela oferta, que é justamente uma maneira de pensar a relação entre a escala individual e a coletiva (WOLTON, 2012, p.19).
\end{abstract}

A televisão generalista seria ainda essencial para a coesão nacional, possibilitando uma identificação dos públicos com as representações feitas pela TV. De forma que, quanto mais generalista for a mídia, maior será a representatividade perante a sociedade e mais fortemente será desempenhado seu papel de comunicador nacional.

Não haveria então democracia de fato, na ausência de mídias generalistas que privilegiem uma oferta mais ampla possível. "Privilegiar uma concepção do grande público da televisão é se inscrever em uma certa tradição democrática, pois o grande público da televisão não é outra coisa, nas áreas da cultura e da comunicação, do que a figura do sufrágio universal" (WOLTON, 2012, p.67).

Além do fortalecimento da democracia, há ainda o fator social. As mídias generalistas favorecem o chamado laço social, conceito usado para designar as relações de uma comunidade nacional. Trata-se de uma coletividade simbólica construída diariamente através de mídias como a televisão. É aí que encontramos, então, o espírito da televisão: ela promove 
uma aliança entre o indivíduo e a comunidade.

\begin{abstract}
A questão fundamental é: para que serve a televisão a um indivíduo que não é nunca passivo diante da imagem e que somente retém o que ele quer? Ela serve para se ter o que falar. A televisão é um formidável instrumento de comunicação entre os indivíduos. O mais importante não é o que é visto, mas o fato de se ter o que falar. A televisão é um objeto de conversação. Fala-se entre si, mais tarde, em todos os lugares (WOLTON, 2012, p.69, grifos do autor).
\end{abstract}

Dominique Wolton ao abordar a figura dos solitários (solidões interativas) coloca a televisão como um meio capaz de amenizar a solidão do individuo, o colocando diante de um vínculo que liga a todos de igual forma, não importando a classe social, etnia ou religião. "Qual atividade é atualmente assim tão transversal? Caso a televisão não existisse, seria o sonho de muitos inventar um instrumento suscetível de reunir todos os públicos" (2012, p. 70).

Se a importância da televisão generalista é a de unir a população e trazer ao público uma variada gama de assuntos aos quais, pressupõe-se, todos devem tomar conhecimento, fortalecendo assim, um Estado democrático, o atual panorama aponta para o fortalecimento de novas mídias, mais segmentadas, como a internet, por exemplo. As mídias que oferecem conteúdo on demand estão cada vez ganhando mais espaço e a predileção dos públicos, que podem construir uma programação mais personalizada, de acordo com o gosto e os interesses de cada um.

\title{
3 AS POSSIBILIDADES DE PERSONALIZAÇÃO DA TV DIGITAL
}

A interatividade proporcionada pelo digital tem a possibilidade de transformar muitas das relações pré-estabelecidas entre o espectador e as emissoras de TV. Segundo Adams, Anand e Fox (2001, online), o relacionamento entre esses dois entes transforma-se em uma trama cada vez mais complexa em que o público tende a posicionar-se de forma cada vez mais ativa no processo comunicativo.

Henry Jenkins (2006) trabalha com o conceito de cultura participativa, expressão usada para explicar a nova relação entre os espectadores e os produtores de conteúdo, onde não existe mais, segundo o teórico, passividade nos espectadores ante aos meios de comunicação. Os papéis de

Rev.Cad. Comun. Santa Maria, v.21, n.1, art 2, p.47 de 57, jan/abr.2017 
consumidores e produtores midiáticos transformam-se, então, em participantes que interagem a todo o momento, baseados num novo conjunto de regras ainda não completamente entendidas.

Os produtores que tratarem os públicos apenas como "público-alvo" ou "usuários" estariam, então, negligenciando seu papel como mediadores e impedindo uma evolução, tanto dos emissores quanto dos públicos. Para Lauro Teixeira (2009) a linha divisória entre produtores e consumidores está cada vez menos clara, os consumidores também são, agora, produtores, o que permite que alguns criem do nada ou modifiquem trabalhos alheios. "Como se vê, uma estrutura setorial que já foi monolítica, na qual profissionais produziam e amadores consumiam, é agora um mercado de duas mãos, no qual qualquer um pode entrar em qualquer campo, a qualquer hora" (ANDERSON, 2006, p.82 apud TEIXEIRA, 2009, p.137).

Além dos públicos participarem mais ativamente do processo comunicacional, a TV digital ainda permite um maior poder de decisão sobre o que, onde e a que momento assistir. $O$ acesso aos conteúdos televisivos, através da cultura participativa, pode ser feita a partir de conceitos como os de "puxamento" ou "captura", isso porque os programas podem ser armazenados em um banco de dados, ficando disponíveis para serem acessados a qualquer momento. Esse recurso transformaria o aparelho televisor de fluxo contínuo de programas em um dispositivo de armazenamento audiovisual. Permitindo o acesso aos produtos audiovisuais televisivos a qualquer momento, teríamos o fim da grade de programação, ou antes, ela se tornaria decisão dos públicos e não mais dos operadores e diretores de TV.

Lauro Teixeira (2009) comenta sobre o poder que o controle remoto já dá aos espectadores de intervir no que estão assistindo, pulando de programação em programação, mas, no entanto, esse poder não tem força suficiente para alterar o fluxo das programações, ou "sequer constituir uma sequência coerente" (TEIXEIRA, 2009, p.89). Mesmo assim, o chamado efeito zapping já demonstra que o espectador está disposto a intervir nas programações sempre buscando uma experiência mais satisfatória e personalizada.

Ao existir a possibilidade de assistir determinado programa a qualquer momento, a audiência passa a ser cada vez menos massiva, tornando-se mais individual e o horário nobre vira o horário do espectador (NEGRO- 
PONTE, 1995). A grande utilização do equipamento de gravação TiVo' nos Estados Unidos, por exemplo, fez as emissoras mudarem o modo de avaliação de audiência². Muitos programas no horário em que são exibidos não têm grande público espectador, mas são gravados para serem exibidos a posteriori.

Outro fator que ratifica a busca por uma programação mais personalizada é o crescimento da TV paga no país. O número de assinantes, no país, quadruplicou nos últimos dez anos, passando de 3,2 milhões em 2002 para 14,3 milhões em maio de 2012, chegando a $24,1 \%$ dos domicílios no Brasil (AGENCIA BRASIL, 2012, online). Se a taxa de crescimento for mantida, em 2014 cerca de metade dos domicílios brasileiros terão acesso à programação da TV fechada. Isso mostra que a população se mostra disposta a pagar para ter acesso a outros tipos de conteúdos, mais focados em nichos.

Portanto, é visível que a ação do digital sobre a televisão pode imprimir novos comportamentos, possibilitando uma personalização dos conteúdos em questão de dias, horários e temas. Ademais, é notável o interesse por produtos audiovisuais mais segmentados, visto o crescimento da televisão fechada e de mídias como a internet. Diante desse movimento, o ensaio investiga se as possibilidades de interação da TV digital sentenciam a televisão generalista à morte.

\section{A INTERATIVIDADE É A SENTENÇA DE MORTE DA TV GENERA- LISTA?}

Diante das possibilidades de personalização do conteúdo permitidas pela TV digital e da crescente popularidade dos canais e das mídias segmentadas, a televisão generalista promotora do laço social, fortalecedora da democracia e de uma "cola social" estaria ameaçada? Como todo crime precisa de evidências, vamos a elas.

A primeira evidência se remete a um dos mitos da televisão digital: a de que todos irão querer interagir a todo o momento, não existindo mais o espectador passivo. Newton Cannito (2010) afirma que a TV do futuro (e

$1 \quad$ TiVo é Trata-se de um aparelho de vídeo que permite aos usuários capturar a programação televisiva para armazenamento em disco rígido (HD), para visualização posterior.

2 Disponível em: <http://oglobo.globo.com/cultura/revistadatv/>. Acesso em: 06 Nov. 2011.

Rev.Cad. Comun. Santa Maria, v.21, n.1, art 2, p.49 de 57, jan/abr.2017 
a cada dia podemos ver esse "futuro" mais próximo) será dotada de interatividade, mas que alguns critérios precisam ser levados em conta: interatividade não significa necessariamente qualidade e nem todas as pessoas irão querer sempre tornar-se produtoras de conteúdo ou mesmo interagir sempre que possível na programação.

O autor faz um paralelo como o fato de grande parte da população ter câmera de vídeo e, nem por isso, ter se tornado cineasta; o mesmo acontece com a escrita: nem todos que sabem ler e escrever tornaram-se escritores. Com a televisão digital é a mesma coisa: não é por que a televisão dá opção de interagir que todos irão fazê-lo. Walter Cybis (2007) diferencia quatro tipos de comportamento frente ao meio. Há o espectador convencional que irá continuar assistindo a TV de forma mais passiva, interagindo o mínimo possível. O segundo perfil é o do espectador digital que usufruirá das facilidades que a digitalização proporciona como a alta definição, grades eletrônicas de programação e informações adicionais. Tem-se o espectador interativo, para o qual, os programas convencionais disputarão atenção com os serviços interativos e, por fim, o usuário interativo, que não tem como meta assistir a TV, somente usá-la como dispositivo de interação.

Mesmo diante da televisão analógica, Wolton já acredita existir um comportamento interativo³ ${ }^{3}$ mas uma interação não imediata (diferente

3 André Lemos (1997) trabalha com outros conceitos e divisões quanto à interatividade. Para o autor, ela está divida em cinco diferentes níveis:

Nível o - é o estágio em que a televisão expõe imagens em preto e branco e dispõe de um ou dois canais. A ação do espectador resume-se a ligar e desligar o aparelho, regular o volume, brilho e contraste e trocar de um canal para outro.

Nível 1 - a televisão ganha cores, maior número de emissoras e controle remoto - o zapping vem anteceder a navegação contemporânea web. Ele facilita o controle que o espectador tem sobre o aparelho, mas, ao mesmo tempo, o prende ainda mais a televisão.

Nível 2 - alguns equipamentos periféricos vêm acoplar-se à televisão, como o videocassete, as câmeras portáteis e os jogos eletrônicos. O telespectador ganha novas tecnologias para apropriar-se do objeto televisão, podendo agora também ver vídeos e jogar, e das emissões, podendo gravar programas e vê-los ou revê-los quando quiser.

Nível 3 - já aparecem sinais de interatividade de características digitais. O telespectador pode então interferir no conteúdo por meio de telefonemas (como foi o caso do programa "Você Decide", da Rede Globo de Televisão), por fax ou correio eletrônico.

Nível 4 - é o estágio da chamada televisão interativa em que se podem participar do conteúdo a partir da rede telemática em tempo real escolhendo ângulos de câmera, diferentes encaminhamentos das informações, etc (Lemos, 1997, p.3, online).

Rev.Cad. Comun. Santa Maria, v.21, n.1, art 2, p.50 de 57, jan/abr.2017 
da proporcionada pelos meios digitais). Assistimos a um programa e reagimos a ele, em comentários, conversas, redes sociais (fenômeno da segunda tela ${ }^{4}$ ). Uma interação mais rápida pode reprimir a reflexão, necessária para a criação de um pensamento mais crítico.

Mesmo diante da capacidade de interagir a todo o momento e instantaneamente, Arlindo Machado (1995) caracteriza a televisão como sendo um meio que se dá à custa da "acomodação e do anestesiamento do decodificador, que já recebe a informação pronta e carregada de módulos de ordem aos quais é impossível resistir" (1995, p. 61). Dessa forma, é possível perceber que mesmo com a possibilidade de interação a grande maioria da população ainda permanecerá com um comportamento mais passivo diante da TV, ou seja, nem sempre a postura de espectador passivo será substituída pela de participante ativo.

Quanto à democracia fortalecida pela TV generalista, Wolton acredita que esta não exista sem comunicação, visto que é o local de discussão dos interesses políticos e, ao mesmo tempo, termômetro de um Estado democrático. Tudo isso se dá pelo fato de que a atividade de assistir televisão é compartilhada por todos: pobre e ricos, população da cidade e do campo, do centro e da favela.

Quando falamos em televisão digital interativa o software criado para essa função, o Ginga, foi desenvolvido pensando justamente na promoção da inclusão social e digital da população, elementos essenciais a democracia:

O reconhecimento do Ginga, inclusive, veio primeiro do exterior. Por ser uma linguagem declarativa, ela é de muito fácil utilização, não exige um programador especialista. E com isso podemos ter pessoas não especialistas gerando conteúdos interativos, o que torna um lado da inclusão social possível, que é a produção de conteúdo. Ela não precisa ficar na mão daqueles que exigem conhecimento muito grande. Isso vai permitir que as camadas mais pobres possam além de gerar um conteúdo se apropriar também da produção deste conteúdo (SOARES, 2011, entrevista, online).

4 A Segunda Tela (ou Second Screen) é um complemento em tempo real à televisão (a primeira tela). Ao utilizá-la, seja em computadores, smartphones ou tablets, o "teleinternauta" recebe informações extras e pontos importantes sobre o assunto que está sendo tratado no programa que está no ar no momento.

Rev.Cad. Comun. Santa Maria, v.21, n.1, art 2, p.51 de 57, jan/abr.2017 
O pesquisador e professor Luiz Fernando Soares (2011) comenta que a inclusão social e digital obtida através da televisão deve chegar às classes $D$ e $E$, visto que somente $3 \%$ dos públicos dessas classes têm acesso a um computador e que $84 \%$ nunca usou um computador ou teve acesso à internet. Neste mesmo contexto, das classes D e E, 95\% têm aparelho televisor ${ }^{5}$. É claro que a televisão não pode ser usada como único meio para se chegar a uma inclusão social e digital, mas pode contribuir para solucionar, ou antes, amenizar, as discrepâncias sociais brasileiras.

É importante notar que a televisão generalista não é vinculada a tecnologia e, sim, ao conteúdo. Dominique Wolton (2012) nega uma abordagem tecnicista dos meios de comunicação, deixando claro que existem outros fatores, como a cultura e as condições político-econômicas interagindo a todo o momento com as mídias.

O principal elemento da televisão não é, então, a tecnologia, mas o conteúdo. É o conteúdo que une a todos, que representa a todos, dos pobres aos ricos, dos mais letrados aos menos, do norte ao sul. E pensando que esse conteúdo atinge, diariamente, mais de 90\% do território nacional, segundos dados do IBOPE criado pela TV.

[...] a televisão é a mídia brasileira mais importante. Em menos de quatro décadas, o vídeo transformou a face do país, modificou os hábitos diários do povo, revolucionou a política, impôs profundas alterações na cultura, estabeleceu parâmetros de comportamento, afetou a fala e inovou a língua dos brasileiros. [...] A televisão se transformou na principal fonte de informação e notícia para as mais amplas camadas de espectadores de todos os níveis, todas as idades, todas as classes, de todos os rincões deste país (SALLES, 2010, p.18).

E é o conteúdo que permitirá a televisão generalista sobreviver, mantendo assim, o laço social, a "cola”, que une a população. E esse conteúdo vem agendando outras mídias, mais segmentadas, como a internet. Um exemplo notório foi o caso da telenovela Avenida Brasil, exibida no horário das nove horas, pela Rede Globo. A novela em questão apresentou expressivos números de audiência, chegando à marca de 50 pontos no 
painel nacional do IBOPE` o que equivale a oito em cada dez televisores ligados e sintonizados para assistir à exibição dos capítulos. Mas, seu sucesso não se manteve ligado somente à TV generalista.

Um levantamento realizado pela Seekr ${ }^{8}$, empresa que monitora marcas nas mídias sociais, encontrou sete mil menções a termos ligados à novela, no Twitter, durante 24 horas entre os dias 9 e 10 de agosto de 2012. O índice é considerado bastante elevado, ainda mais se pensarmos que a própria emissora não investe para que isso aconteça.

E na semana do maior julgamento da história, o mensalão, a capa da Veja, foi... Avenida Brasil! [...] A questão então é a repercussão que a novela tem tido fora da telinha, assuntos e temas únicos da novela têm invadido as diferentes redes sociais e o dia-a-dia até mesmo de quem não assiste o folhetim. Se você é brasileiro e não sabe quem é Carminha, há algo errado. $O$ extraordinário é que outras novelas que tiveram ibope igual ou maior, como a anterior "Fina Estampa", não tiveram toda essa comoção nem no mundo real nem no virtual (UOL, 2012, online).

No Facebook, há 286.149 fãs e a hasgtag \#oioioi (que faz referência à música de abertura da novela) já chegou a ser mencionada mais de 1,3 mil vezes por dia no Twitter. Já as personagens principais, Rita/Nina ${ }^{9}$ e Carminha ${ }^{10}$, são mencionadas, em média, mil vezes por dia no microblog, segundo o site Topsy ${ }^{11}$, que mede a recorrência de palavras. No dia do $100^{\circ} \mathrm{ca}$ pítulo, que prometia uma virada na história \#OiOiOi10o atingiu o topo dos Trending Topics ${ }^{12}$ mundial. Outras hashtags como \#avenidabrasil, \#congela, \#EsseCadinho, \#MistériosdeCarminha e \#Capítulo100 ficaram entre os dez assuntos mais citados no Twitter no dia da exibição do centésimo episódio da novela.

O caso Avenida Brasil é um exemplo, mas outras novelas e programas

7 apud REVISTA VEJA, edição 2281, p.153, 2012.

8 Disponível em: <http://seekr.com.br/>. Acesso em: 25 ago. 2012.

9 Personagem da atriz Débora Falabella.

10 Personagem da atriz Adriana Esteves.

11 O site Topsy quantifica o número de menções a uma determinada palavra no Twitter. A medição é diária. Disponível em: <http://analytics.topsy.com/?q=carminha\%2Cnina\%2Crita\&period=1\%20month>. Acesso em: 24 ago. 2012.

12 Assuntos mais comentados no mundo.

Rev.Cad. Comun. Santa Maria, v.21, n.1, art 2, p.53 de 57, jan/abr.2017 
de televisão também são constantemente comentados e debatidos em redes sociais. Percebe-se, então, que mesmo diante das mídias segmentadas, o conteúdo da televisão aberta e generalista tem sido bastante influente. O mais relevante não é necessariamente o aparato tecnológico, mas o conteúdo. É o conteúdo que sustenta a mídia generalista, permitindo que o laço social seja transportado também para a internet, por exemplo.

\section{APONTAMENTOS FINAIS}

Um dos motivos para pensar no fim da TV generalista é a crença de que, com as possibilidades interativas, todos irão querer interagir a todo o momento, o que se mostra infundado. Mesmo na internet onde a possibilidade de interação é fomentada, nem sempre interagimos: não é sempre que comentamos as publicações de blogs, ou que compartilhamos vídeos, ou mesmo que, fazemos comentários em publicações do Facebook, por exemplo. O cinema, por exemplo, também passou por um processo de digitalização e nem por isso interagimos (em um grau mais elevado de interação) com os filmes ou ainda a impossibilidade de interatividade matou o cinema. É importante ressaltar que interatividade não é qualidade.

É preciso lembrar ainda que a televisão se propõe a algo distinto da interação a todo o momento. Quantas vezes ligamos a televisão enquanto fazemos outras coisas, como estudar, preparar o almoço, limpar a casa, entre outras atividades? A televisão, diferente dos outros meios, serve de companhia as pessoas, o "barulho" por ela produzido dá uma sensação de não estar sozinho, ter mais pessoas em casa. A TV faz companhia.

Certamente, a maior evidência de que a televisão generalista seguirá tendo seu espaço (e, por conseguinte, seguirá fortalecendo a democracia e o laço social) é o valor do seu conteúdo. É o conteúdo que supera as questões tecnológicas, como a inclusão da tecnologia digital, e é ele que fará com que a televisão siga sendo televisão. É no conteúdo que percebemos a diversidade cultural da sociedade. É onde tomamos maior conhecimento do diferente e das diferenças.

É o conteúdo que permitirá que o laço social siga sendo fortalecido e supere inclusive a necessidade de um encontro físico para que as conversas sobre os programas de TV aconteçam. É aí que a televisão pode se beneficiar das mídias sociais, por exemplo, para estender o laço ou forta-

Rev.Cad. Comun. Santa Maria, v.21, n.1, art 2, p.54 de 57, jan/abr.2017 
lecê-lo através da internet. Até mesmo as mídias mais segmentadas são influenciadas pelos conteúdos da TV generalista. Portanto, a digitalização da televisão generalista só fortalecerá seu conteúdo, permitindo que com o digital, a TV se torne mais TV e siga fortalecendo o que Dominique Wolton acredita serem as principais contribuições desse meio: o laço social e o fortalecimento da democracia. 
CADERNOS DE COMUNICAÇÃO

UNIVERSIDADE FEDERAL DE SANTA MARIA

REFERÊNCIAS

ADAMS, M., ANAND, P. \& FOX, S. Interactive television: Coming soon to a television near you. 2001. Disponível em: <http://www.ranjaygulati.com/new/research/INTERACT. pdf >. Acesso em: 10 Fev. 2013.

CANNITO, Newton. A televisão na era digital. Interatividade, convergência e novos modelos de negócio. São Paulo: Summus, 2010.

CYBIS, Walter; BETIOL, Adriana Holtz; FAUST, Richard. Ergonomia e usabilidade. Conhecimentos, métodos e aplicações. São Paulo: Novatec, 2007.

CRAIDE, Sabrina. Aumento da renda e melhores ofertas permitiram crescimento de TV por assinatura. Agência Brasil. 2013, online. Disponível em: <http://agenciabrasil.ebc. com.br/noticia/2012-06-24/aumento-da-renda-e-melhores-ofertas-permitiram-crescimento-de-tv-por-assinatura>. Acesso em: 15 Jun. 2013.

JENKINS, Henry. Cultura da convergência. São Paulo: Aleph, 2006.

MACHADO, Arlindo. A arte do vídeo. São Paulo: editora Brasiliense, 1995.

NEGROPONTE, Nicholas. A Vida Digital. São Paulo: Companhia das letras, 1995.

REVISTA DA TV. Após apelo dos fãs, Fox renova Fringe por mais uma temporada. 0 Globo. Disponível em: <http://oglobo.globo.com/cultura/revistadatv/>. Acesso em: 06 Nov. 2011.

REVISTA VEJA. São Paulo, Editora Abril, semanal, 2012. Edição 2281.

SALLES, Mauro Salles. O Brasil e a televisão. São Paulo: Sumus, 2010.

SOARES, Luiz Fernando Gomes. Ginga para todos; entrevista. [31 de outubro de 2011]. Fortaleza: Jornal O Povo. Entrevista concedida a Émerson Maranhão. Disponível em: < http://www.opovo.com.br/ >. Acesso em 6 Nov.2011.

TEIXEIRA, Lauro. Televisão Digital - Interação e Usabilidade. Goiânia: Ed. UCG, 2009.

UOL NOTÍCIAS. "Nina Congelada" vira febre em fotos de perfis nas redes sociais; veja (e aprenda a fazer). Disponível em: <http://migre.me/asvjE>. Acesso em: 10 jul. 2012.

WOLTON, Dominique. Internet e depois? Uma teoria crítica das novas mídias. Porto Alegre: Sulina, 2012.

Rev.Cad. Comun. Santa Maria, v.21, n.1, art 2, p.56 de 57, jan/abr.2017 


\section{Mateus Vilela}

Doutorando e mestre em Comunicação Social pela PUCRS, bolsista PSDE - Universidade do Minho, Portugal, graduado em Artes visuais bacharelado em Design Gráfico pela UFPEL.

E-mail:mateusdvilela@gmail.com

RECEDIDO EM: 10/04/2016

ACEITO PARA PUBLICAÇÃO: 9/06/2016 